\title{
Synthesis of multi-walled carbon nanotube in a gas-solid fluidized bed
}

\author{
Seung Yong Son, Dong Hyun Lee ${ }^{\dagger}$, Sang Done Kim*, Su Whan Sung**, Young Soo Park*** and Jong Hun Han*** \\ Department of Chemical Engineering, Sungkyunkwan University, 300 Chunchun, Jangan, Suwon 440-746, Korea \\ *Department of Chemical and Biomolecular Engineering \& Energy and Environment Research Center, \\ Korea Advanced Institute of Science and Technology, Daejeon 305-701, Korea \\ **Department of Chemical Engineering, Kyungpook National University, Daegu 702-701, Korea \\ ***Iljin Nanotech Co., Kayang Techno Town 1487, Seoul 157-810, Korea \\ (Received 6 November 2005 • accepted 17 March 2006)
}

\begin{abstract}
Multi-walled carbon nano-tubes (MWCNTs) were produced by acetylene decomposition on Fe-catalyst in a fluidized bed reactor $(0.056 \mathrm{~m}$-ID $\times 1.0 \mathrm{~m}$-high) with a sintered metal distributor ( $40 \mu \mathrm{m}$ pore size). The Fe-catalysts were tested in decomposition of the different ratios of acetylene, hydrogen and nitrogen at the temperature range of 823-973 K. The physical properties of the carbon nano-tubes were determined by HR-TEM, SEM and Raman spectroscopy. The multi-walled carbon nano-tubes produced from the fluidized bed reactor are sub-aggregates and entangled with each other. The synthesized MWCNTs have outer diameters of a few tens of nanometers at 823-973 K. It has been found that the synthesized CNT agglomerates are in good condition with less amorphous carbon with the reaction time of 30 to 60 minutes from the analyses of Raman Spectra, SEM and TEM, The ratio $\left(\mathrm{I}_{D} / \mathrm{I}_{G}\right)$ of amorphous carbon $\left(\mathrm{I}_{D}=\right.$ $\left.1,295 \mathrm{~cm}^{-1}\right)$ and crystalline carbon $\left(\mathrm{I}_{G}=1,590 \mathrm{~cm}^{-1}\right)$ range from 1.15 to 1.49 .
\end{abstract}

Key words: Carbon Nanotubes, Fluidized Beds, Catalytic Chemical Vapor Deposition

\section{INTRODUCTION}

Since carbon nanotube (CNT) were discovered by Dr. Iijima in 1991, they have become a popular research topic all over the world because of their unique physical and electrical properties such as high electric conductivity, thermal and chemical stability, mechanical strength, name but a few [lijima, 1991; Oh, 2004]. Currently, many countries are providing governmental support to such studies on the synthesis and application of CNT for acquiring competitiveness in the 21 century advanced electronic and information industries and high-functional complex materials. The various methods to synthesize CNT include Arc discharge, plasma, laser vaporization, gas phase synthesis, thermal chemical vapor deposition (TCVD). However, these methods have difficulty producing enough quantity of CNTs that will be needed by many industries in the near future. Thus, a new synthetic method by means of employing fluidized beds is an attractive one. Catalytic chemical vapor deposition (CCVD) method by using fluidized beds is found to be the right choice for CNT mass production because the powder catalysts may provide larger contacting area with reacting gases compared to the CCVD method using general catalyst substrates [Mauron et al., 2003]. Currently, fluidized bed reactors are utilized in many industrial processes because of their unique advantages over other types of reactors. However, it is difficult to handle nano particles in a gas-solid fluidized bed reactor because the attractive force between nano particles is stronger than fluid mechanical movement. In this case, this particles aggregate together and this plays a very important role in the CNT synthesis. In other words, the catalyst particles can easily contact with the cracked carbon that helps nano tube growth [Wang

To whom correspondence should be addressed.

E-mail: dhlee@skku.edu et al., 2002]. Therefore, Wang et al. [2002] reported that the CCVD method using fluidized bed reactors is the best way for mass production of CNT. In addition, the fluidized bed operation can overcome the difficulties of device plugging and damage to the reactor wall with deposition of carbon materials in the fixed bed operation [Perez-Cabero et al., 2003]. The physical property of CNT varies with the synthesized temperature, time, flow velocity, and the composition ratio. Thus, it is very important to determine the effects of synthesis time (15-240 min), temperature and gas velocity on the CNT yield, growth form, its purity and growth rate.

\section{EXPERIMENTAL}

Experiments were carried out in a fluidized bed reactor $(0.053 \mathrm{~m}-$ I.D. $\times 1.0 \mathrm{~m}$-height) made of stainless steel (type: 310 ) tube as shown in Fig. 1. A gas distributor, a sintered metal plate with $40 \mu \mathrm{m}$ of the pore diameter, was installed on the bottom of the column. The reactor was composed of a bottom furnace to preheat the reacting gas, an upper insulated furnace that supplied reaction heat and a trap system installed to collect entrained particles. The upper and bottom furnace had a separate temperature controller to control internal temperature of the column. To measure internal reactor temperature, four thermocouples were installed at $0.04 \mathrm{~m}, 0.14 \mathrm{~m}, 0.50 \mathrm{~m}$, and $0.75 \mathrm{~m}$ from the distributor. The monitored temperature was recorded on a computer through an A/D converter. Entrained particles coming out of the reactor were collected at an acryl trap device filled with water on the vent. The temperature in the lower part of the gas distributor was maintained at $380{ }^{\circ} \mathrm{C}$ to prevent heat decomposition of acetylene. The mass flow controllers (MFC) were used to control volumetric flow rate of $\mathrm{H}_{2}, \mathrm{~N}_{2}$ and $\mathrm{C}_{2} \mathrm{H}_{2}$. The total gas flow rates at room temperature were $33.3 \times 10^{-6} \mathrm{~m}^{3} / \mathrm{s}$ and $50.0 \times$ $10^{-6} \mathrm{~m}^{3} / \mathrm{s}$ in the experiment. The volumetric flow ratio of $\mathrm{N}_{2} / \mathrm{H}_{2} / \mathrm{C}_{2} \mathrm{H}_{2}$ 


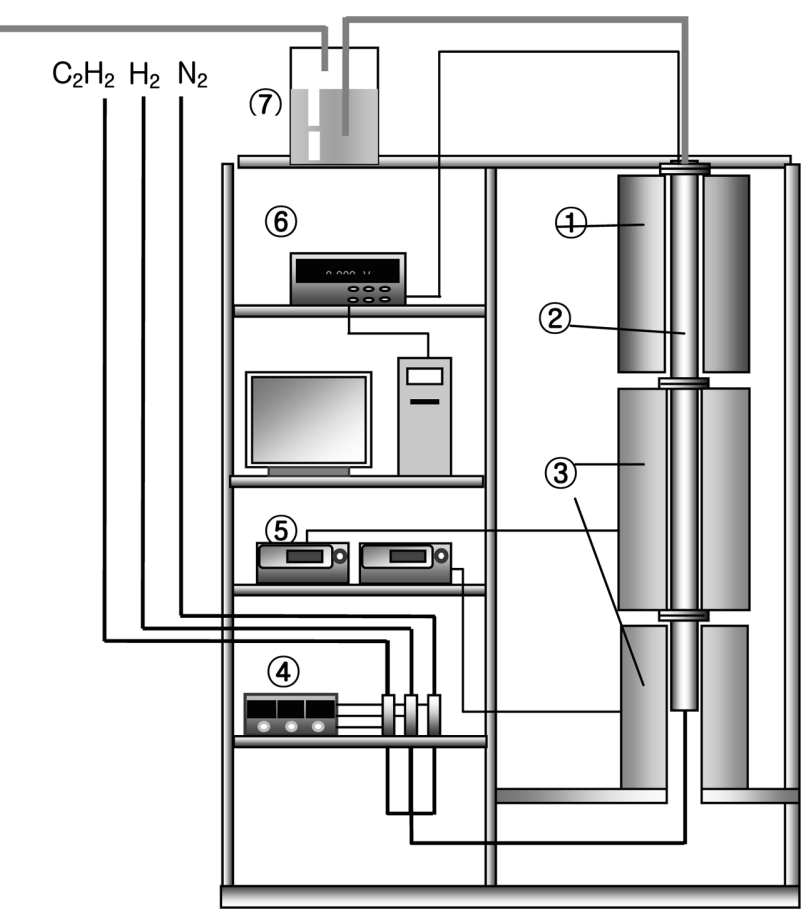

Fig. 1. Schematic diagram of the experimental setup.
(1) Insulator
(5) Furnace controller
(2) Stainless steel column
(6) $\mathrm{A} / \mathrm{D}$ converter
(3) Furnace
(7) Trap system
(4) Mass Flow controller

was $1: 2: 1$. The catalyst, $\mathrm{Fe} / \mathrm{Mo} / \mathrm{Al}_{2} \mathrm{O}_{3}$, has size distribution in the range of 45-150 $\mu \mathrm{m}$ having an average diameter of $107.9 \mu \mathrm{m}$ with a bulk density of $1,000 \mathrm{~kg} / \mathrm{m}^{3}$ and $30 \mathrm{~g}$ of the catalyst was charged in each experiment. After the reaction was completed, the products inside the reactor and the trap device were collected. The collected samples were measured and analyzed by SEM, TEM, and Raman spectra.

\section{RESULTS AND DISCUSSION}

Temperature variation inside the reactor is shown in Fig. 2 at 600

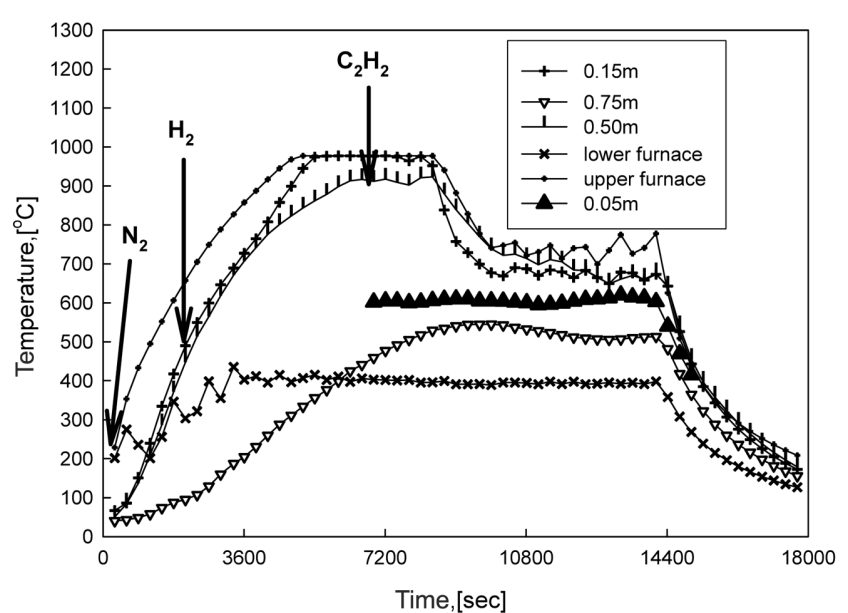

Fig. 2. Temperature variation inside the reactor when CNT was synthesized for 2 hours at $600{ }^{\circ} \mathrm{C}$.

${ }^{\circ} \mathrm{C}$ for CNT synthesized for 2 hours. As can be seen, the temperature at 0.15 and $0.5 \mathrm{~m}$ above the gas distributor falls down rapidly with temperature at 30 minutes after acetylene was injected into the bed. Also, the temperature along the bed height decreases significantly. That may indicate the bed expansion occurs rapidly within 30 minutes after reaction begins.

The SEM images of the CNT agglomerate produced after the reaction with the catalyst of $\mathrm{Fe} / \mathrm{Mo} / \mathrm{Al}_{2} \mathrm{O}_{3}$ at $600{ }^{\circ} \mathrm{C}$ using acetylene as a carbon source at the total volumetric gas flow rate of $50.0 \times$ $10^{-6} \mathrm{~m}^{3} / \mathrm{s}$ and the flow ratio of $\mathrm{N}_{2} / \mathrm{H}_{2} /$ acetylene at $1: 2: 1$ for 2 hours are shown in Figs. 3(a) and (b). As can be seen, the CNT agglomerate has irregular forms having an average diameter of $590 \mu \mathrm{m}$ with the bulk density of $96 \mathrm{~kg} / \mathrm{m}^{3}$ that is 5 times as large as that of the catalyst. Using propylene as a carbon source, Wang et al. [2002] made CNT agglomerates. However, Yu et al. [2003] used a catalyst of $\mathrm{Fe} / \mathrm{Mo} / \mathrm{Al}_{2} \mathrm{O}_{3}$ having an average diameter of $110 \mu \mathrm{m}$ with a bulk density of $1,100 \mathrm{~kg} / \mathrm{m}^{3}$ in a fluidized bed reactor where they used propylene as a carbon source and the average diameter of the produced CNT agglomerates is $497 \mu \mathrm{m}$.

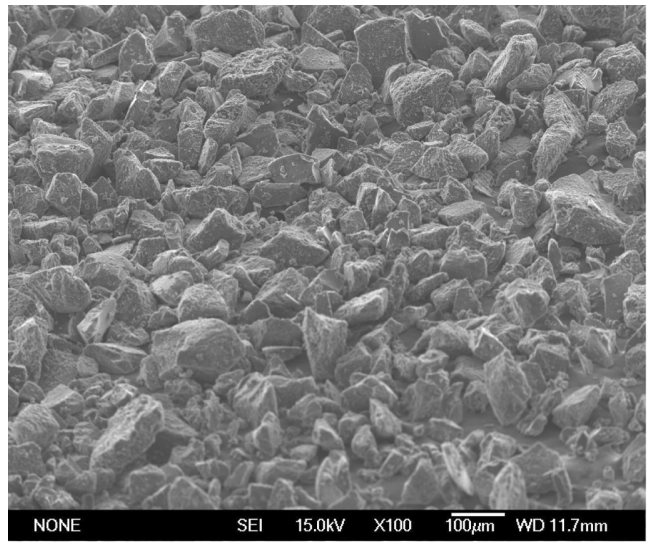

(a) Fresh Fe / Al catalyst (scale bar size : $100 \mu \mathrm{m}$ )

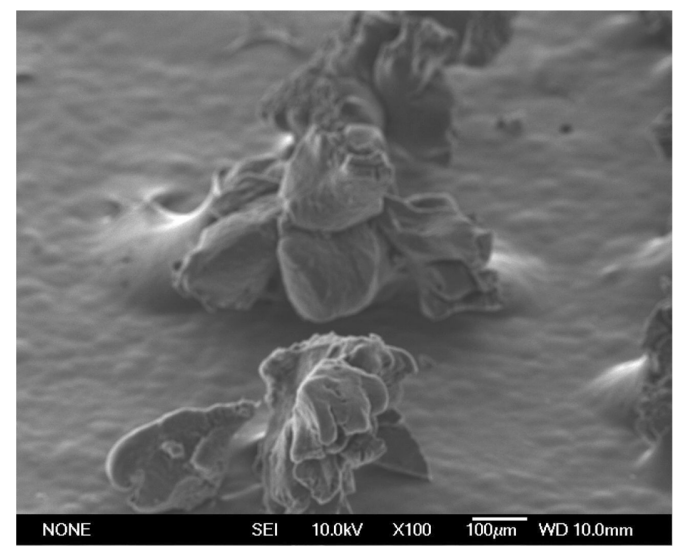

(b) CNT agglomerate after reaction (scale bar size : $100 \mu \mathrm{m}$ )

Fig. 3. SEM images of (a) the initial catalytic powders and (b) CNT agglomerates after the reaction. 


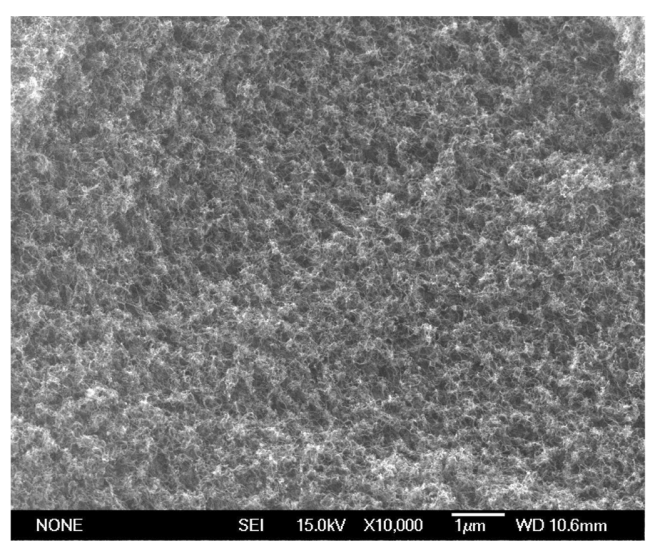

(a) $\mathrm{x} 10,000$

(scale bar size : $1 \mu \mathrm{m}$ )

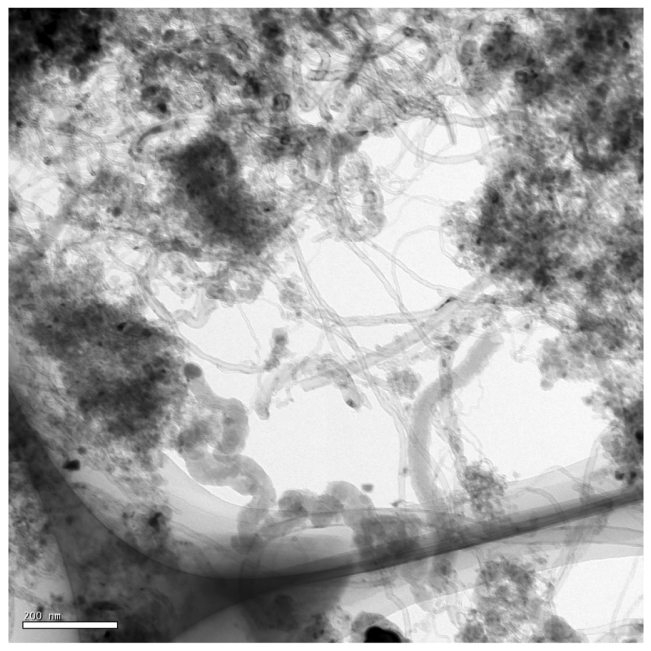

(c) $\mathrm{x} 140,000$

(scale bar size : $200 \mathrm{~nm}$ )

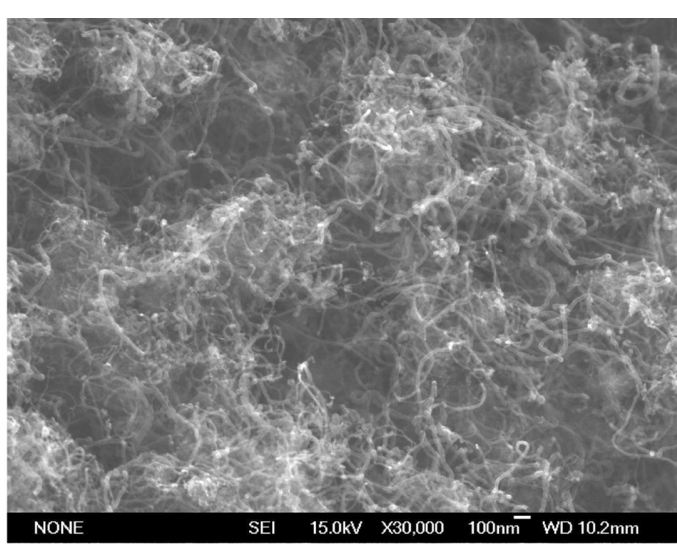

(b) $x$ 30,000

(scale bar size : $100 \mathrm{~nm}$ )

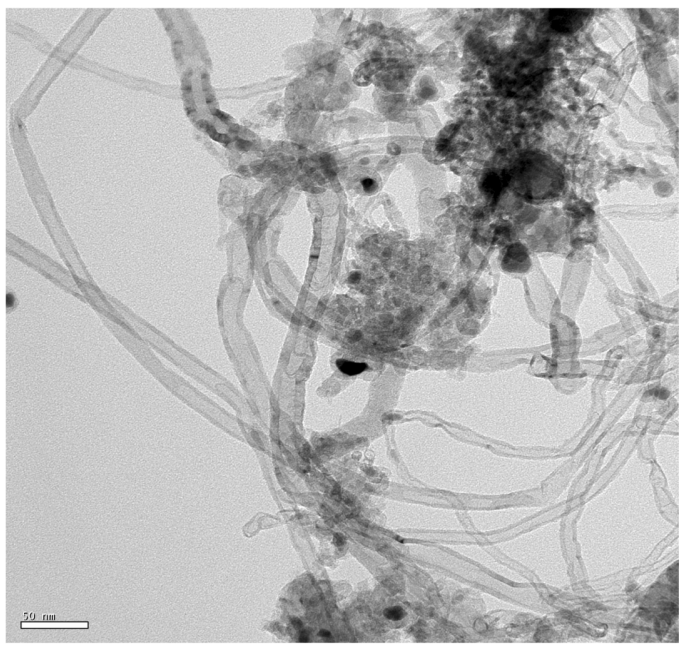

(d) $x$ 374,000

(scale bar size : $50 \mathrm{~nm}$ )

Fig. 4. SEM and TEM images of surface of the CNT agglomerate.

The SEM ( $a$ and $b$ ) and TEM images (c and d) of the CNT agglomerate surface (Fig. 3b) is shown in Fig. 4. Generally, the CNTs grow uniformly on an ordinary substrate in the vertical direction from the CVD method. However, the CNTs from the fluidized bed are entangled without order regardless of synthesis condition as shown in Fig. 4(b).

The conversion and the volume increasing rate of CNT products that synthesized at $33.3 \times 10^{-6} \mathrm{~m}^{3} / \mathrm{s}$ and $50.0 \times 10^{-6} \mathrm{~m}^{3} / \mathrm{s}$ for 2 hours at

Table 1. Comparison of the experimental data between No. 1 and No. 2 (catalyst amount: $30 \mathrm{~g}$, reaction temperature: 873.15 $K$, reaction time: $120 \mathrm{~min}$ )

\begin{tabular}{lccc}
\hline \hline Item & Unit & No. 1 & No. 2 \\
\hline Vol. flow rate & $\mathrm{m}^{3} / \mathrm{s}$ & $33.3 \times 10^{-6}$ & $50.0 \times 10^{-6}$ \\
Total mass produced & $\mathrm{g}$ & 67.2 & 84.1 \\
Conversion & $\%$ & 57.9 & 56.1 \\
Initial vol. (catalyst) & $\mathrm{ml}$ & 30 & 30 \\
Final vol. (product) & $\mathrm{ml}$ & 220 & 520 \\
Vol. increase & $\%$ & 633 & 1633 \\
\hline
\end{tabular}

$600{ }^{\circ} \mathrm{C}$ are summarized in Table 1 . As can be seen, with $30 \mathrm{~g}$ of the catalyst, conversion rates of carbon source are about same $57.89 \%$ and $56.08 \%$. However, their volume increase rates are very different as $633 \%$ at $33.3 \times 10^{-6} \mathrm{~m}^{3} / \mathrm{s}$ and $1,633 \%$ at $50.0 \times 10^{-6} \mathrm{~m}^{3} / \mathrm{s}$. These results indicate that the proper flow rate for the growth of CNT agglomerate is $50.0 \times 10^{-6} \mathrm{~m}^{3} / \mathrm{s}$ to produce proper size of CNT for good fluidization since particle entrainment became severe at the gas flow rate over $50.0 \times 10^{-6} \mathrm{~m}^{3} / \mathrm{s}$. Therefore, the maximum gas flow rate was fixed at $50.0 \times 10^{-6} \mathrm{~m}^{3} / \mathrm{s}$ that is about $6 \mathrm{U}_{m f}$ of the catalyst at $600{ }^{\circ} \mathrm{C}$.

The growth rate of carbon, conversion and volume increasing rate of carbon source with synthesis time at $600{ }^{\circ} \mathrm{C}$ and the volumetric flow rate of $50.0 \times 10^{-6} \mathrm{~m}^{3} / \mathrm{s}$ are shown in Table 2 . As can be seen, the growth rates of catalyst, conversion of the carbon source, and volume increasing rate of the products increase with reaction time.

The products synthesized at $600{ }^{\circ} \mathrm{C}$ and $50.0 \times 10^{-6} \mathrm{~m}^{3} / \mathrm{s}$ at different reaction times are shown in Fig. 5 in terms of Raman spectra. In the Raman spectrum analysis, the D-band at wave length of 1,295 $\mathrm{cm}^{-1}$ indicates the existence of amorphous carbon and the G-band at wave length of $1,590 \mathrm{~cm}^{-1}$ indicates crystalline carbon. In Table 3 , 
Table 2. Conversion, volume increasing ratio and growth rate of CNT with reaction time

\begin{tabular}{cccc}
\hline \hline $\begin{array}{c}\text { Reaction } \\
\text { time, [min] }\end{array}$ & $\begin{array}{c}\text { Conversion, } \\
{[\%]}\end{array}$ & $\begin{array}{c}\text { Volume } \\
\text { increase, [\%] }\end{array}$ & $\begin{array}{c}\text { Growth rate, } \\
\text { [g-carbon/g-cat. s] }\end{array}$ \\
\hline 15 & - & 15 & - \\
30 & 19.79 & 317 & 0.00530 \\
60 & 39.06 & 483 & 0.01046 \\
120 & 56.08 & 1,500 & 0.01502 \\
240 & 73.61 & 1,933 & 0.01972 \\
\hline
\end{tabular}

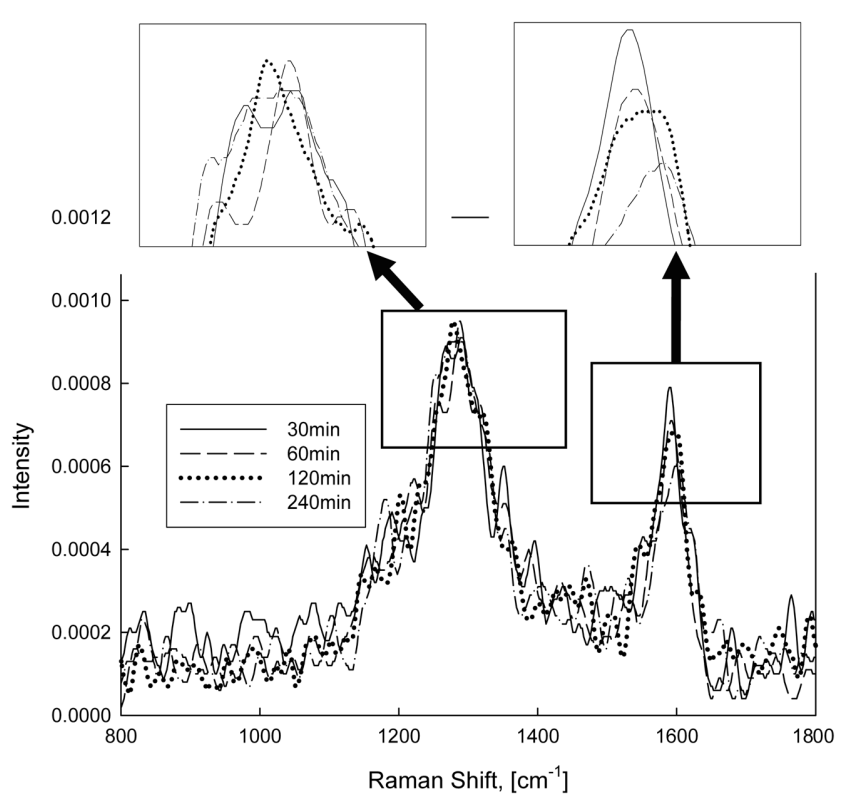

Fig. 5. Raman spectra of the synthesized CNTs at $600{ }^{\circ} \mathrm{C}$ and $50.0 \times$ $10^{-6} \mathrm{~m}^{3} / \mathrm{s}$ as a function of reaction time.

Table 3. The intensity ratio $\left(I_{D} / I_{G}\right)$ of D-and G-bands in the Raman spectra analysis

\begin{tabular}{cccc}
\hline \hline Reaction time, [min] & $\mathrm{I}_{D}$, [a.u.] & $\mathrm{I}_{G}$, [a.u.] & $\mathrm{I}_{D} / \mathrm{I}_{G},[-]$ \\
\hline 15 & 0.00352 & 0.00307 & 1.147 \\
30 & 0.00091 & 0.00079 & 1.152 \\
60 & 0.00095 & 0.00071 & 1.338 \\
120 & 0.00095 & 0.00067 & 1.418 \\
240 & 0.00091 & 0.00061 & 1.492 \\
\hline
\end{tabular}

the highest points of D-band $\left(\mathrm{I}_{D}\right)$, G-band $\left(\mathrm{I}_{G}\right)$ and the ratio of $\mathrm{I}_{D} / \mathrm{I}_{G}$ are presented where the numbers comes from the study of Qian et al. [2003]. From this table, it can be seen that the quantity of crystalline CNTs among the total products decreases and the quantity of amorphous carbons increases with reaction time. Qian et al. [2003] reported that the intensity ratio of $\mathrm{D}$ to $\mathrm{G}$ lines increases with increasing reaction time as in the present study that may indicate the CNTs contain serious defects since the high ratio reflects higher defects inside the carbon layers.

\section{CONCLUSION}

Multi-walled carbon nano-tubes (MWCNTs) were produced by acetylene decomposition on Fe-catalyst in a fluidized bed reactor. The multi-walled carbon nano-tubes produced are agglomerated and entangled with each other from the fluidized bed reactor. The synthesized MWCNTs have outer diameters of a few tens of nanometers at 823-973 K. From the analyses of the MWCNT by Raman Spectra, SEM and TEM indicate the CNT agglomerates in good condition with less amorphous carbon synthesized at the reaction time of 30 to $60 \mathrm{~min}$. The ratio $\left(\mathrm{I}_{D} / \mathrm{I}_{G}\right)$ of amorphous carbon $\left(\mathrm{I}_{D}=1,295\right.$ $\left.\mathrm{cm}^{-1}\right)$ and crystalline carbon $\left(\mathrm{I}_{G}=1,590 \mathrm{~cm}^{-1}\right)$ ranges from 1.15 to 1.49 .

\section{ACKNOWLEDGMENTS}

This work was supported by Korea Research Foundation Grant (KRF-2004-003-D00076).

\section{REFERENCES}

Iijima, S., 'Helical microtubules of graphitic carbon,' Nature, 354, 56 (1991).

Mauron, Ph., Emmenegger, Ch., Sudan, P., Wenger, P., Rentsch, S. and Züttel, A., "Fluidized-bed CVD synthesis of carbon nanotubes on $\mathrm{Fe}_{2} \mathrm{O}_{3}$ /MgO,' Diamond and Related Materials, 12, 780 (2003).

Oh, E.-S., "van der Waals interaction energies between non-planar bodies,' Korean J. Chem. Eng., 21, 494 (2004).

Perez-Cabero, M., Rodriguez-Ramos, I. and Guerrero-Ruiz, A., "Characterization of carbon nanotubes and carbon nanofibers prepared by catalytic decomposition of acetylene in a fluidized bed reactor,' Journal of Catalysis, 215, 305 (2003).

Qian, W., Liu, T., Wei, F., Wang, Z., Luo, G, Yu, H. and Li, Z., 'The evaluation of the gross defects of carbon nanotubes in a continuous CVD process,' Carbon, 41, 2613 (2003).

Wang. Y., Wei, F., Luo, G., Yu, H. and Gu, G., "The large-scale production of carbon nanotubes in a nano-agglomerate fluidized-bed reactor,' Chemical Physics Letters, 364, 568 (2002).

Yu, H., Zhang, Q., Wei, F., Qian, W. and Luo, G, “Agglomerated CNTs synthesized in a fluidized bed reactor: Agglomerate structure and formation mechanism," Carbon, 41, 2588 (2003). 